Article

\title{
Protective Pathways: Connecting Environmental and Human Security at Local and Landscape Level with NLP and Geospatial Analysis of a Novel Database of 1500 Project Evaluations
}

\author{
Nathan Morrow ${ }^{1} \mathbb{D}$, Nancy B. Mock ${ }^{1}$, Andrea Gatto ${ }^{2,3,4, * \mathbb{C}}$, Julia LeMense ${ }^{5}$ and Margaret Hudson ${ }^{6}$ \\ 1 School of Public Health and Tropical Medicine, Tulane University, New Orleans, LA 70112, USA; \\ nmorrow@tulane.edu (N.M.); mock@tulane.edu (N.B.M.) \\ 2 College of Business \& Public Management, Wenzhou-Kean University, Wenzhou 325060, China \\ 3 Natural Resources Institute, University of Greenwich, Central Avenue, Chatham Maritime ME4 4TB, UK \\ 4 Centre for Studies on Europe, Azerbaijan State University of Economics (UNEC), Baku AZ1001, Azerbaijan \\ 5 Independent Researcher, New York, NY 10009, USA; julia.lemense@gmail.com \\ 6 Independent Researcher, Denver, CO 80203, USA; hudson.meg@gmail.com \\ * Correspondence: a.gatto@greenwich.ac.uk
}

\section{check for}

updates

Citation: Morrow, N.; Mock, N.B.; Gatto, A.; LeMense, J.; Hudson, M. Protective Pathways: Connecting Environmental and Human Security at Local and Landscape Level with NLP and Geospatial Analysis of a Novel Database of 1500 Project Evaluations. Land 2022, 11, 123. https://doi.org/10.3390/ land 11010123

Academic Editor: Hossein Azadi

Received: 19 November 2021

Accepted: 28 December 2021

Published: 12 January 2022

Publisher's Note: MDPI stays neutral with regard to jurisdictional claims in published maps and institutional affiliations.

Copyright: (C) 2022 by the authors. Licensee MDPI, Basel, Switzerland. This article is an open access article distributed under the terms and conditions of the Creative Commons Attribution (CC BY) license (https:// creativecommons.org/licenses/by/ $4.0 /)$.

\begin{abstract}
Localized actionable evidence for addressing threats to the environment and human security lacks a comprehensive conceptual frame that incorporates challenges associated with active conflicts. Protective pathways linking previously disciplinarily-divided literatures on environmental security, human security and resilience in a coherent conceptual frame that identifies key relationships is used to analyze a novel, unstructured data set of Global Environment Fund (GEF) programmatic documents. Sub-national geospatial analysis of GEF documentation relating to projects in Africa finds $73 \%$ of districts with GEF land degradation projects were co-located with active conflict events. This study utilizes Natural Language Processing on a unique data set of 1500 GEF evaluations to identify text entities associated with conflict. Additional project case studies explore the sequence and relationships of environmental and human security concepts that lead to project success or failure. Differences between biodiversity and climate change projects are discussed but political crisis, poverty and disaster emerged as the most frequently extracted entities associated with conflict in environmental protection projects. Insecurity weakened institutions and fractured communities leading both directly and indirectly to conflict-related damage to environmental programming and desired outcomes. Simple causal explanations found to be inconsistent in previous largescale statistical associations also inadequately describe dynamics and relationships found in the extracted text entities or case summaries. Emergent protective pathways that emphasized poverty and conflict reduction facilitated by institutional strengthening and inclusion present promising possibilities. Future research with innovative machine learning and other techniques of working with unstructured data may provide additional evidence for implementing actions that address climate change and environmental degradation while strengthening resilience and human security. Resilient, participatory and polycentric governance is key to foster this process.
\end{abstract}

Keywords: environmental security; climate change; resilience; human security; biodiversity; conflict

\section{Introduction}

Policies intended to address the global threats facing people and the planet are implemented in landscape and local-scale projects [1]. The importance of these projects as the means to achieve policy goals cannot be understated. Scientists are no longer simply issuing a series of warnings about the level and nature of our imperilment. The scientific community is increasingly calling for the translation of their findings into actionable guidance to be incorporated into localized interventions to address both the negative outcomes and the drivers of climate change and environmental degradation endangering ecological life and 
livelihood support systems [2]. Nearly twelve percent of people worldwide are reported to be severely food insecure [3]. Hunger increased sharply in 2020 due to climate-related disasters, economic trouble made worse by the COVID-19 pandemic and violent conflict [4]. The Uppsala Conflict Data Program (UCDP) reported that 2020 also had the highest number of active conflicts since 1946 [5]. The Intergovernmental Panel on Climate Change's (IPCC) special report on Climate Change and Land concluded that anthropogenic climate change has negatively impacted food security primarily from the increased frequency of extreme weather events, and that the extreme events lead to environmental degradation further undermining resilience [6]. Continental-scale longitudinal statistical analysis over the last decade from Africa shows that climate disaster-related hunger is exacerbated by conflict that negatively impacts production and slows recovery [7]. The authors suggest additional research beyond statistical association is required to understand the relative frequency, inter-scale dynamics and strength of different causal pathways linking observed feedback between conflict, poverty and environmental degradation.

Climate change and biodiversity loss are global crises that together pose the greatest threats to the continued existence of humans due to ecological collapse [8]. By pursuing conservation-oriented projects to protect biodiversity and a different set of socio-economic focused interventions to promote climate change adaptation and mitigation, multinational and national institutions have not systematically integrated these activities and interventions. This segmented focus often created disconnected silos of environmental protection policy and associated measurement approaches [9]. While older research often conformed to these sub-disciplinary divisions, more recent research increasingly finds strong causal feedback relationships showing the interconnectedness of biodiversity and climate change adaptation and resilience [10]. Biodiversity is foundational to climate change adaptation [10], and climate change-related extreme weather is a key contributor to biodiversity loss [11]. Practical requirements emerging through the popularization of nature-based solutions in addressing a wide range of environmental degradation and resilience issues has increasingly led to integrating biodiversity and climate change across research, policy formation and policy implementation activities [12].

The Global Environment Facility (GEF) is the largest multinational source of financial resources for environmental protection. Conveners of the 1992 Earth Summit in Rio de Janeiro created the GEF to support intergovernmental engagement that promotes sustainability by addressing the underlying issues of inequality, poverty and overconsumption that drive environmental problems such as land degradation, biodiversity loss and climate change. From 1991 to 2017, the GEF invested 17.9 billion USD for environmental protection while leveraging 93.2 billion USD from its partners to implement more than 4500 projects with environmental protection goals [13]. During this time period, the GEF invested more than four billion US dollars, one-third of its global portfolio, in countries enduring contemporaneous armed conflict [14]. The geospatial analysis in this paper was commissioned to inform a position paper presented in preparation for the GEF 7 replenishment focused on Environmental Security [13]. Ratner (2018) [13] cited the lack of actionable conceptual framing appropriate to develop programming approaches and effectiveness metrics as the key challenges to mainstreaming environmental security in GEF projects.

The complex inter-relationships among conflict, climate change, environmental protection and human security are yet to be researched and implemented in large publicly funded portfolios, including the GEF $[15,16]$. Ref. [16] Exposing this dearth of research, in this paper we employ multiscale and meta-evaluative analyses of the GEF portfolio to glean lessons from funded environmental protection activities about what encourages and what hinders environmental security. In assessing the data, the authors use a unified security and resilience concept frame to identify what might be missing and needed to realize the desired environmental security outcomes. We seek specifically to understand: where are the GEF projects and extant security-compromising conflicts co-located? Are there underlying factors or causal relations that explain this spatial correlation? We interrogate documentation originating from those designing and implementing projects in 
a broad variety of contexts to better understand the utility of environmental security for addressing goals related to human wellbeing, environmental protection and resilience. The results inform and our discussion of 'protective pathways' for resilience and sustainability acknowledging multiple perspectives of stakeholders closest to the targeted vulnerable geographies that have nuanced understandings of the complexities conflict presents in the programmatic context.

The work proceeds as follows. Section 2 explores the policy implementations and connections between environmental security, human security and resilience. Section 3 describes the methods used in this inquiry. Following, Section 4 presents the results. Section 5 discusses the main findings, identifies study limitations and future research, and offers brief conclusions.

\section{Towards an Analytical Frame Mapping Conceptual Connections between Environmental Security, Human Security and Resilience Relevant for Policy-Makers and Stake Holders}

\subsection{From Nation-State to Human-Centered Focus of Environmental Security}

The earliest discussions on environmental security began taking place in the context of national security debates in the wake of the Cold War and in the face of the oil crises in the 1970s [17]. The phrase "environmental security" is believed to have first entered the international policy debate in 1987 with the publication of the Brundtland Report entitled Our Common Future $[18,19]$. Environmental degradation was cast as the next major threat to national security; however, the fear that environmental degradation could be a national (and international) security threat was identified as early as the 1970s [20]. In contrast, the United Nations Development Programme (UNDP) identified environmental security as one of seven main categories of threats to human security in 1994 [21].

Understanding the evolution of environmental security discourse is important because national security logic still permeates some of the discourse and affects efforts to achieve environmental security [22]. Unlike food or livelihood security, environmental security has been slower to embrace a human-centered approach and to include analysis of associations with household and individual level wellbeing [23]. Discussions and analyses of attempts to achieve environmental security through policy and programmatic efforts reveal unchallenged beliefs and assumptions about causality, and often ignore the systems that influence adverse environmental outcomes and the individual and collective action logics that perpetuate them [24-26].

Two provocative and pervasive discourses revolve around the "resource curse" [27-29]. Resource abundance, particularly of high-value extractable resources, has been proposed as a direct cause of conflict because (a) the revenue upon sale can fund and sustain violent conflict [30] or (b) they are available for exploitation and sale by the controlling party to economies of the northern hemisphere seeking to sustain consumption patterns [31]. Conversely, resource scarcity brought about by degradation or depletion of fundamental resources like cropland, water and fuel sources, has also been proposed as a cause of conflict in the face of increased demand [32] or where the distribution of resources is not aligned with the populations who rely on them due to complex factors [33].

Neo-Malthusian scarcity arguments remain persuasive (even for the GEF) but are problematic. First, there are no consistent statistical association or evidence of causal linkages between conflict variables and environmental degradation variables coming out of statistical analysis of large environmental and climate data sets produced through modeling or synoptic remote sensing of temporal changes in the land or weather [29]. Second, violent conflict is strongly influenced by "poverty" as a variable and tends to mask other variables, like scarcity or degradation. Third, the case studies that have been cited as the evidence for scarcity causing violent conflict start from the outcome and allow for no variation in the dependent variable. Fourth, the findings of case studies are subject to interpretation often leading to different conclusions [29].

Thus far, the utility of environmental security as a concept for framing policy and operationalizing programs has been hampered by confusion in definitions and problems 
with obtaining and synthesizing a robust empirical evidence base [34]. Further research may confirm a causal linkage between scarcity and conflict, but it is surely indirect and mediated by other variables. The social psychology underpinnings of conflict are complex, involving deprivation and identity, and lead to framing of the problems in terms of intergroup dynamics, skewing in favor of findings of conflict [29]. In fact, a growing body of research finds equitable management of natural resources makes scarcity and competition less likely to lead to conditions of fragility and violent situations [35].

\subsection{Human Security as an Overarching Framework for Implementing International Policy and Programs}

The concept of human security rose to prominence in 1994 in anticipation of the World Summit for Social Development in 1995 [21]. The UNDP is largely credited with coining the term "human security" in its 1994 Human Development Report [21]. In identifying environmental security as one of seven main categories of security (Economic security, Food security, Health security, Environmental security, Personal security, Community security, Political security), UNDP embedded environmental security into the discourse of human security. UNDP also identified environmental protection, preservation and regeneration as key goals and top priorities of sustainable human development.

Nearly 20 years later, UN member states articulated a shared understanding of human security in 2012. Upon adopting General Assembly resolution 66/290, states affirmed "that human security is an approach to assist Member States in identifying and addressing widespread and cross-cutting challenges to the survival, livelihood and dignity of their people". The beginning of this paradigm shift is evident in the 1970 Declaration on the Strengthening of International Security, in which Member States acknowledged the fundamental role that respect for human rights of all peoples plays in achieving international security [36].

\subsection{Social-Ecological Resilience Application to Policy Implementation and Programming}

Resilience recently has emerged as a set of capacities that modulate risks, shocks and stresses to facilitate sustainable development [37]. Resilience is increasingly articulated as a goal across a range of international programs recognizing the key roles that shocks and risk play as challenges to sustainable development. A search of the GEF project database returns a result of 4768 projects that include the word 'resilience' in their documentation. Frequently associated with the ability to bounce back from climate-related disaster, the concept is often applied in fact-specific, resource-specific or discipline-specific ways depending on the organization or context [38]. Norris et al., (2008) [39] suggest that the best way to employ resilience is as a metaphor for the complex set of capacities, feedbacks and ability to learn from, and change in the face of, shocks and stress that maintain the integrity of the community and desirable wellbeing outcomes.

Wellbeing outcomes are often the proposed outcome measurement of human centered resilience [40,41]. In 2007, Berkes again reviewed a wide and diverse literature to identify four clusters of factors relevant to building resilience: (1) learning to live with change and uncertainty, (2) nurturing various types of ecological, social and political diversity for increasing options and reducing risks, (3) increasing the range of knowledge for learning and problem-solving and (4) creating opportunities for self-organization [42]. Resilience shall be connected to participatory and polycentric governance [43]. In 2010, Bahadur et al. [44] review 16 overlapping and sometimes conflicting conceptualizations of resilience to distill ten main characteristics of resilient systems embracing a wide range of subjects from equity, diversity, preparedness, participation, learning, governance and consciousness of uncertainty and cross-scalar dynamics. A recent example of synthesizing the characteristics of resilient systems together into a framework for building resilience through a participatory process is offered by Berkes and Ross (2013) [45].

Several authors emphasize the coupled human ecological systems aspects of resilience. Based on earlier resilience work focusing on management of forests or other ecological 
systems, much of the research on socio-ecological resilience has maintained the environment and environmental services as the foundation of desirable wellbeing and social outcomes [46-49].

\subsection{Protective Pathways for Human Security, Sustainability and Resilience}

Protection, often enshrined in a legal framework or framed as a basic right, is the outcome of security. The challenge then for applied research on Environmental Security is not to find cases that confirm preexisting policy assumptions, but to expand the observational base to analyze the security outcomes of policy and program logic in diverse geographies and scales. It is an unlikely, but empirical, question whether the logic of conflict over nonrenewable resources as a threat to integrity and stability of a state (national security perspective) also directly applies to renewable resources at a local level $[31,50,51]$. There are important differences between resilience approaches to safeguard livelihoods from existential threats to the earth as a system and those focused on environmental change and climate-related disaster at local levels [52,53]. Human security as an approach to securing rights and dignity as the foundation, in the broadest sense, of protection and peace has clear implications for the promotion of sustainability in conflict-affected contexts, but policy-relevant evidence is not consistently documented $[26,54,55]$. Different policyaligned programmatic approaches, proven on the front lines of project implementation in conflict-affected areas, can provide the broader observational basis for defining environmental security pathways reflecting policy and programmatic assumptions that produce the desired resilience and sustainability outcomes.

\subsection{Seeking Policy-and Program-Relevant Pathways Informed by Environmental Protection, Human Security and Resilience}

A graphical representation of the security and resilience concepts that informed our analysis of GEF project documents is presented in Figure 1. Although resource scarcity driven analysis of conflict can be particularly relevant in contexts where high value nonrenewable resources are being extracted, other environmental security concepts are more directly relatable to human security more generally. Risk and threat identification concepts from environmental security form a basis mitigating negative impacts of extreme events associated with environmental change on wellbeing and human security. When the risk identification is systematized, it becomes a foundation for adaptation that results in sustainably improved wellbeing outcomes. Similarly, environmental security focus on equitable access and securing rights presents a clear pathway contributing to livelihood security with implications for energy, water and food security [56]. For the desirable environmental security outcomes of peace and stability to be maintained over the long-term, resilience capacity must also be a focus of policy intervention and resultant program design. Community resilience capacities are the foundation to enabling protective pathways to environmental and human security.

Identification of the (re)occurrence of these concepts in GEF program documents and then analysis of the relation between the elements are discussed with respect to the Natural Language Processing results. In-depth particularization again highlights the concepts and their relations as the basis for case study analysis presented Sections 4.2-4.4. Finally, this concept map is evaluated for potential explanatory power for spatial association of armed conflict, environmental degradation and landscape level environmental program interventions. 


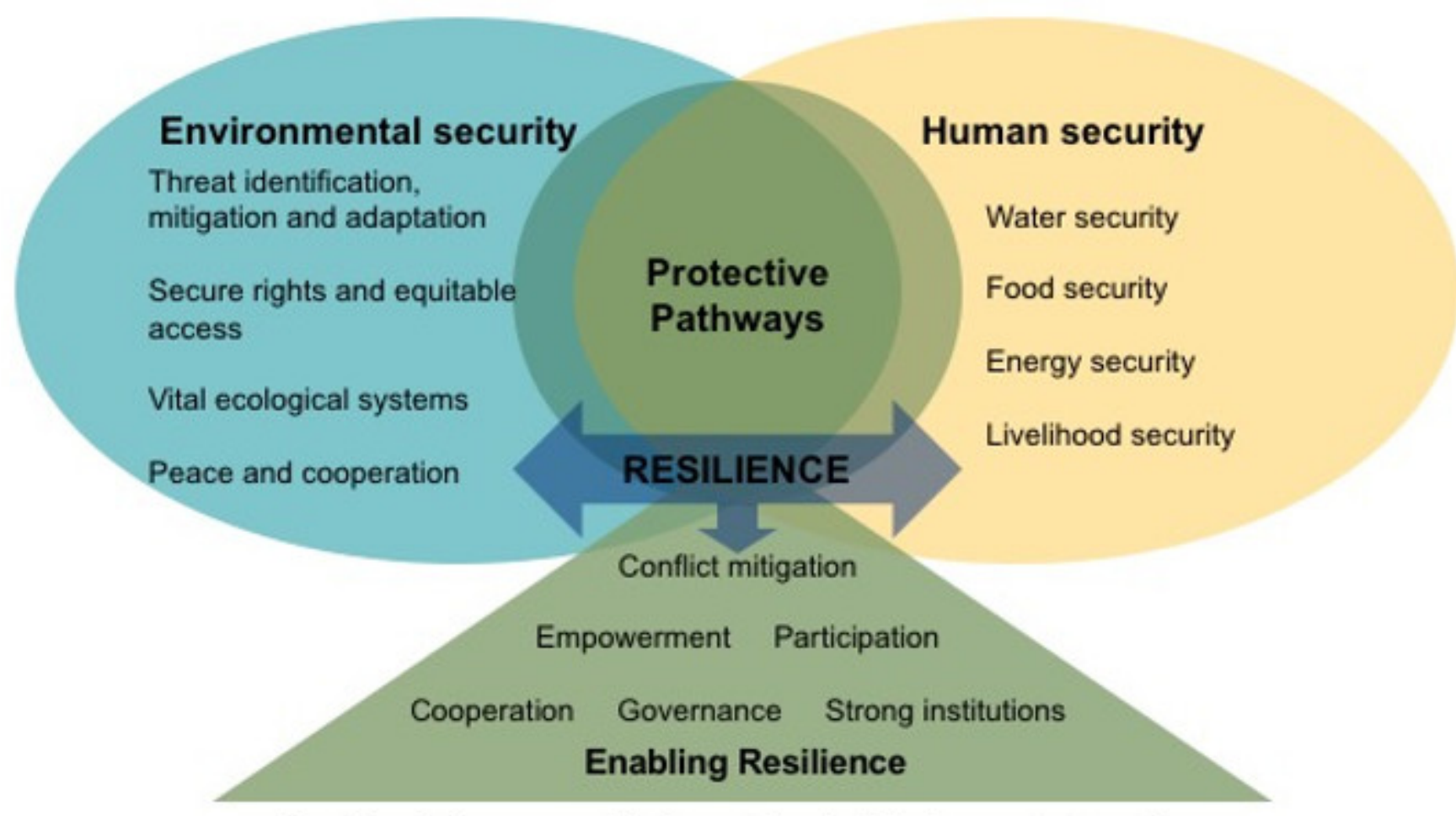

Feedback loops and information hold elements together

Figure 1. Protective pathways frame for identifying relationships between environmental protection, human security and conflict.

\section{Materials and Methods}

Analysis of the GEF's global portfolio was conducted via an iterative and increasingly focused tiered approach to identify specific project evaluations in conflict settings. The GEF online project database at the time of analysis contained single and multi-country projects approved from fiscal year 1991 to 2019 [57]. Natural Language Processing (NLP) is used here to analyze the unstructured textual information from the larger data set of 1500 documents [58]. Machine Learning is used to identify relationships among the conflict related textual elements identified in the training data and recurrent concepts regularly associated to the training data that are present in the larger data set [59]. Geo-spatial analysis of proximity of GEF projects to socially and environmentally marginalized areas affected by conflict

Co-location of conflict and environmental project data was determined by first identifying, and then overlaying, the geospatial layers. This process is commonly used to integrate geospatial data from different sources or that describe different entities in a Geographic Information System [60]. Geocoded subnational GEF environmental protection project locations for Africa have been made available online by AidData [61]. Overall, 416 GEF project sites were available for the spatial analysis. The Armed Conflict Location and Event Data Project (ACLED) has collected geocoded conflict event data for Africa since 1997 [62]. The ACLED dataset includes event data on battles, violence against civilians, riots/protests and significant non-violent military action. The data are freely available for download [63] There were 117,823 conflict events included in spatial analysis. The Global Administrative Unit Layers (GAUL) project made available subnational boundaries and produced a Geographical Information System (GIS) data set (funded by the Bill and Melinda Gates Foundation) [64]. National, secondary and tertiary administrative boundaries are available in a GIS format. The tertiary boundaries correspond to a 'district' level spatial designation. The districts are assumed to be small enough that armed conflict within the same tertiary boundary would clearly impact any other activities in the area. We used QGIS (formerly 
known as Quantum GIS), an open-source geographic information system, for geospatial analysis [65]. We first selected districts from the GAUL dataset that included GEF projects. We then overlaid these districts on the conflict event locations provided by ACLED using a point in polygon procedure to make quantitative measurements.

Content Analysis of GEF Evaluations in Conflict Affected Areas Using the Google Cloud Machine Learning Natural Language Processing Application Interface

Project data were downloaded for each fiscal year of approval (1991 to 2017). Projects were classified according to geographic scope and fiscal year of approval. GEF project documents for 4773 projects were then automatically scraped from the GEF web-based public database and the resulting 17,455 project documents converted to plain text. A subset of 1500 documents, terminal evaluations for Climate Change and Biodiversity projects, was then classified through the Natural Language Processing (NLP) model to quantify the frequency and type of content related to conflict, resilience and sustainability objectives.

The UCDP has recorded major armed conflict events, defined as more than 25 battle deaths, for all countries since 1945 [66]. The UCDP battle-related deaths dataset was utilized in the analysis [67]. This was the only conflict event dataset to cover the entire GEF programming period and all GEF countries. The GEF and UCPD databases were queried for all completed projects that had taken place in conflict affected countries with evaluations, returning 240 evaluations. Initial content analysis was conducted by the researchers to create the training set for the machine learning NLP model. Text entities (sometimes referred to in this paper as "entities"), small phrases or individual words, were then manually classified as conflict-related to refine the training data for NLP model. Each of these 240 evaluations was individually searched for the keywords of "environmental security", "conflict", "unrest", "violence", "stability", and "peace". Where a section on risk existed in the evaluations, these were scanned in greater detail by the researchers for mentions of conflict. Manual extraction of the sentences and clauses from the initial content analysis were then used as an input to the Google Cloud machine learning NLP application interface for analysis.

Through an iterative process that is strengthened by training the classification on larger data sets, the NLP models learn to improve their predictions [68]. The Google Cloud machine learning Natural Language Processing application interface (2018) used to analyze the GEF data base relies on Google's proprietary Vertex artificial intelligence engine. The Vertex engine is built around an approximate nearest neighbor vector similarity matching algorithms. The output of the NLP is lists of phrases and words that are associated with the concepts, in our case conflict concepts, provided in the training data.

Finally, the researchers extracted illustrative cases from the dataset based on the NLP outputs to illustrate the specific pathways for resilience-oriented environmental security programming in socially and environmentally marginalized areas affected by conflict. Conceptual analysis proceeded based on the protective pathways frame for identification of relations between security and resilience-related concepts found in project evaluations. A further relational analysis used the UN Sustainable Development Goals (SDG) 16 targets as a cross reference to explore conflict dynamics and how project activities contributed to or conflicted in achieving security/peace outcomes. Additional documents such as project proposals were consulted in relational analysis and construction of illustrative case summaries.

\section{Results}

Section 4.1 depicts the co-location of GEF environmental protection projects and conflict in maps and presents the results of the geospatial analysis. Section 4.2 presents the results of a content analysis of the GEF database of terminal evaluations. 


\subsection{Co-Location of Environmental Projects and Conflict}

4.1.1. Environmental Projects Increasingly Common in Protracted Internal Conflict and Post-Conflict Settings

GEF projects are frequently implemented in countries and regions experiencing conflict [14]. Although there is variation from year-to-year, Figure 2 time-series on the whole indicates an increasing trend in GEF environmental protection programming in Central and East Africa, South Asia and the Middle East where relatively more frequent armed conflict occurs. The map was created by the authors coding the Administrative level 1 boundaries from the GAUL spatial data set with tabular information from GEF project documents and UCPD conflict data. Overall, more than $62 \%$ of GEF programming has taken place during periods of armed conflict somewhere in the recipient country.

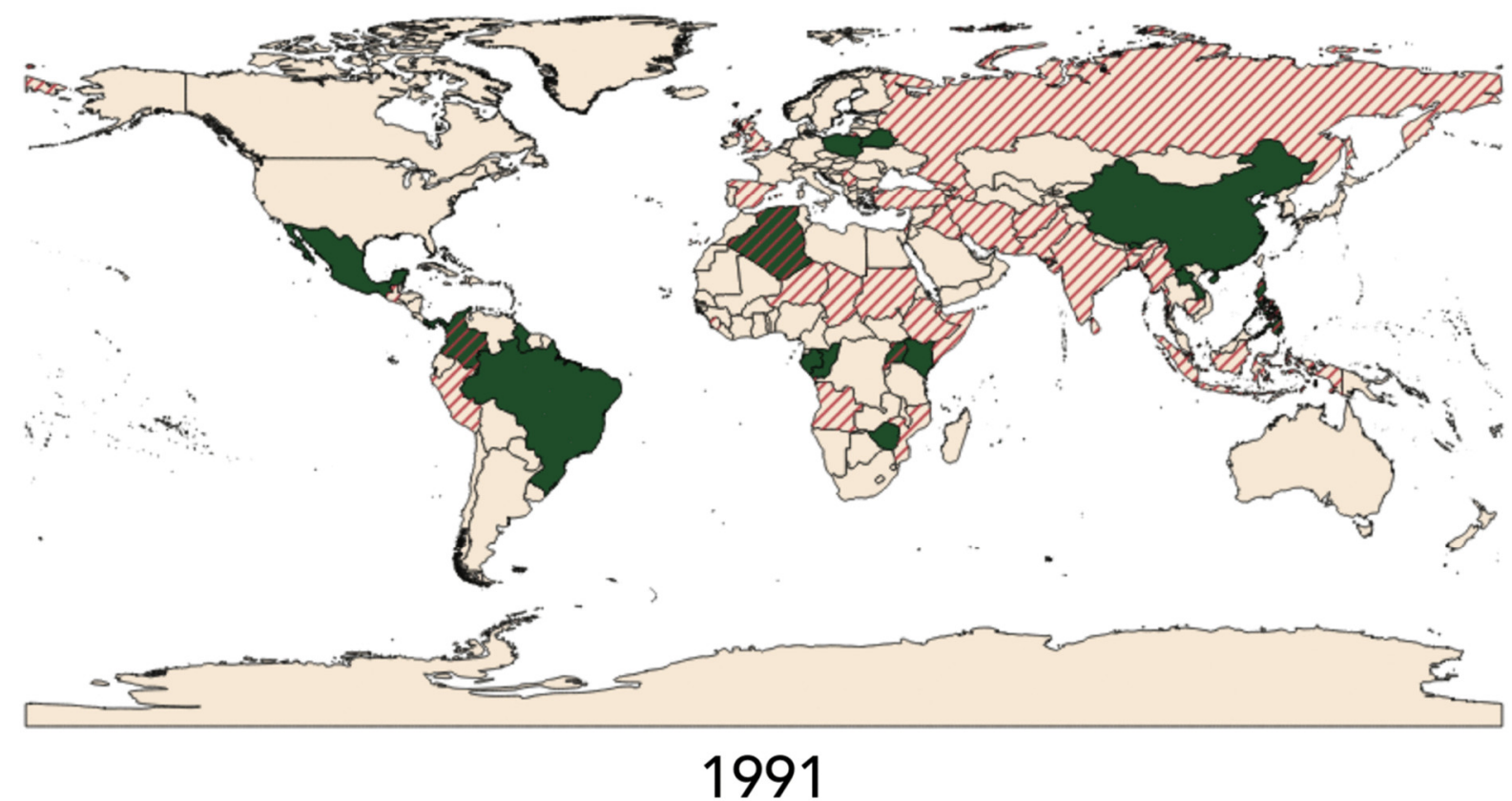

Figure 2. Overlay maps-GEF recipients with single country projects and active conflict (animated gif). GEF recipient country (solid dark green). $Y / /$, country experiencing active armed combat
(red diagonal).

\subsubsection{Sub-National Conflict in Africa Co-Located with Land Degradation Projects}

Sub-national data from GEF African land degradation projects and the ACLED dataset were compared at district level (tertiary administrative units) in Africa. ACLED recorded conflict events in 245 districts since 1997. A subset of GEF projects was geolocated for a large systematic review and therefore locations were available for 226 GEF African land degradation project sites active between 2002 and 2014. Overall, 150 of those project sites were co-located in districts with conflict events. This means that an estimated 73\% of all districts with GEF land degradation projects are co-located with active conflict. Administrative level 3 districts vary in size between countries and within countries, but would represent a localized geographic area or region where the environmental conditions and socio-cultural-economic conditions are relatively similar with shared service centers, transportation infrastructure and resource base. In other words, the project sites and conflict events may not be in the same village but are likely occurring in adjacent communities or watersheds.

Figure 3 left panel depicts a map of the ACLED database conflict events in Africa since 1997. Many events are clustered in the population centers of the Nile River, coastal West Africa and Nigeria. Many conflict events also occurred in the vicinity of Rwanda, Burundi and Eastern Democratic Republic of the Congo. Figure 3 right panel highlights 
the tertiary administrative boundaries for districts with GEF land degradation projects in light orange where there is active conflict and in light green where there is no conflict. GEF land degradation project sites implemented within conflict-affected districts are marked with orange ovals and sites not near conflict are marked as green ovals. Figure 3 right panel also demonstrates the overlay analysis of GEF land degradation project locations and ACLED conflict events to identify the instances of co-location between GEF projects and active conflict. The co-location of projects and conflict is clearly visible in places like Mali, Niger, and Morocco.

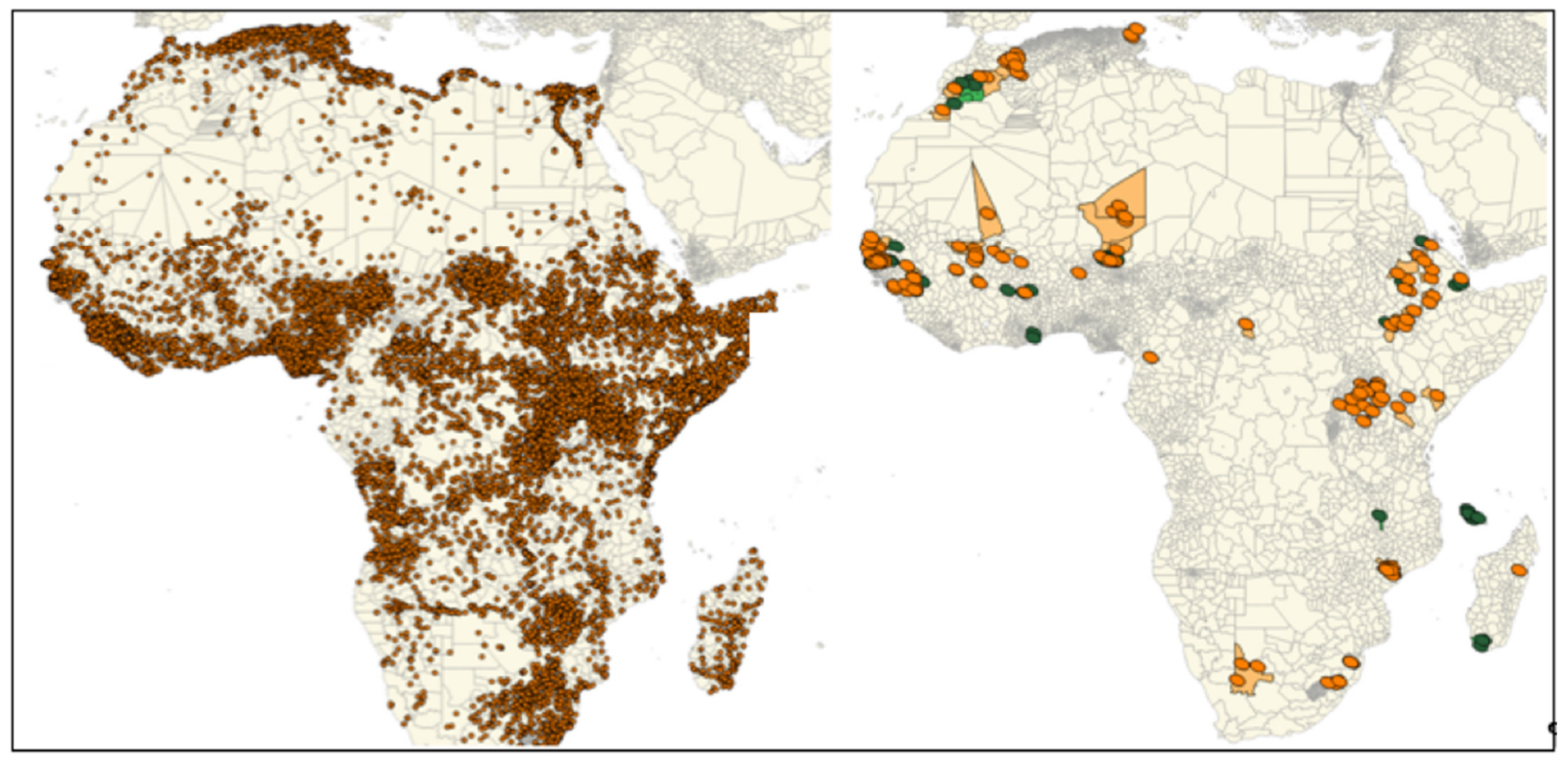

Figure 3. Sub-national co-location of conflict events and GEF projects 2002-2014.

\subsection{Content Analysis of GEF Database of Terminal Evaluations Results of the NLP}

An estimate of the precision of the GEF project evaluation NLP model for identifying conflict related text entities was made by splitting 200 coded text segments into training and validation sets. The results were a specificity of $44.44 \%$ and sensitivity of $40.00 \%$ at a confidence threshold of 0.0001 . The specificity improves to $50.00 \%$ if the threshold is relaxed to 0.23 . It is likely that additional coded text segments would lead to improved precision of the model; however, there are diminishing returns to additional training samples because of the complexity of the concept of conflict, lack of systematic inclusion in a structured format and inconsistent terminology in the available documents.

There were 598 terminal evaluation related documents for projects coded as Climate Change. Figure 4 is a word cloud that represents the results of the NLP model trained on observations of conflict in GEF projects applied to all 589 Climate Change project terminal evaluation documents. The NLP classifier is analogous to a writer selecting a synonym that would each convey the intended message and leaving out other words that are technically synonyms but would be out of context to a reader. To extend the metaphor, all of the phrases captured in the wordcloud represent the synonyms of 'conflict' within the GEF Climate Change programming context. The size and prominence of words reflect the frequency of the entities selected by the NLP model [69].

The terms violence, armed and danger appear relatively infrequently (as depicted in the wordcloud) in comparison with the more frequently conflict-associated entities of crisis, risk, and disaster. One can imagine the wordcloud representing how the evaluation teams wrote about the way conflict impacts environmental protection projects. The impacts 
of conflict on social structure, markets and food security appear prominent. The relation of conflict to disasters, with a particular focus on floods and fires, is pronounced. Many climate change projects are implemented in degraded areas, include afforestation and alternative energy. Conflict in this type of project appears to be associated with issues around the necessities of food, water and fuel. Much of the programming is related to engaging stakeholders in more sustainable management of resources and appears to be affected by conflict based on the model's selection of conflict associated words such as social, communities and governance. It is interesting to note the relative prominence of health and disease entities associated with conflict.

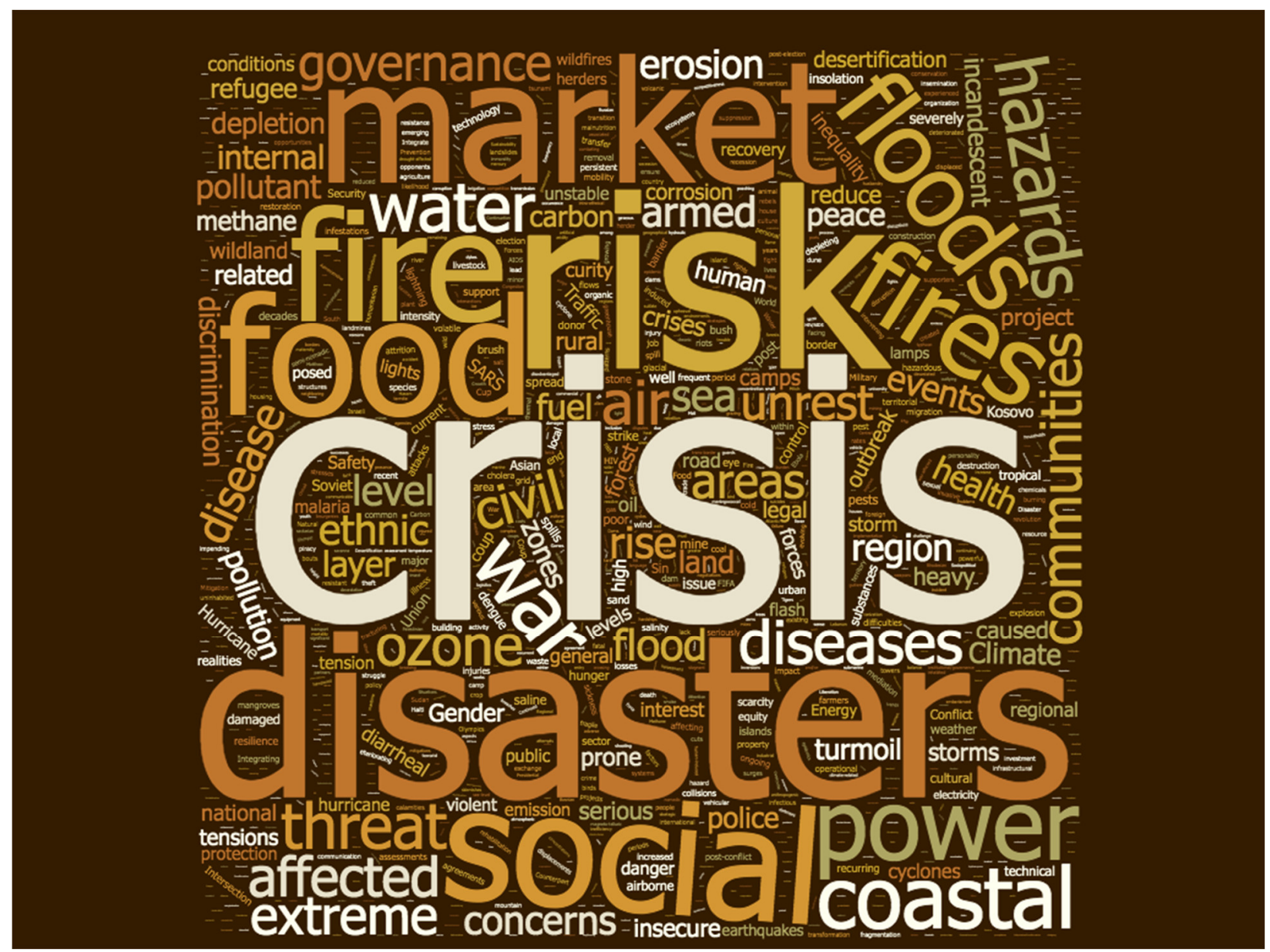

Figure 4. Wordcloud graphic produced from text entities associated with conflict in GEF climate change project terminal evaluations (wordcloud.com accessed 15 April 2018).

Counts of the text entities as phrases and individual words further quantify the initial impressions provided by the wordcloud figure. Conflict is most frequently associated with phrases describing political issues and general political instability (see Table 1. Issues of inequality and gender concerns are the second most frequent set of phrases associated with conflict. The association of natural disasters and conflict is relatively frequently found in the classified entities. Taken together, poverty-related phrases such as food insecurity, vulnerability and extreme poverty are most frequently associated with conflict in the GEF Climate Change project evaluations. 
Table 1. Phrases frequently associated with conflict in climate change project evaluations.

\begin{tabular}{ccc}
\hline \multicolumn{1}{c}{ NLP Results of GEF Climate Change Terminal Evaluations } \\
\hline & $\begin{array}{c}\text { Frequent Phrases Associated } \\
\text { with Conflict }\end{array}$ & $\begin{array}{c}\text { Frequency } \\
\text { (\# of Occurrence in } \\
\text { Evaluations) }\end{array}$ \\
\hline $\begin{array}{c}\text { Resilience Disenablers } \\
\text { (elements related to conflict) }\end{array}$ & $\begin{array}{c}\text { political instability, political risk, } \\
\text { political situation, political crisis }\end{array}$ & 182 \\
\hline & $\begin{array}{c}\text { gender issue, gender inequalities, } \\
\text { gender equality }\end{array}$ & 127 \\
\hline $\begin{array}{c}\text { Environmental Security } \begin{array}{c}\text { Threats } \\
\text { (elements related to conflict) }\end{array} \\
\text { Human Security Threats } \\
\text { (elements related to conflict) }\end{array}$ & $\begin{array}{c}\text { natural disasters, disaster } \\
\text { risk, drought }\end{array}$ & 121 \\
\cline { 2 - 3 } & food insecurity/security & 112 \\
\cline { 2 - 3 } & vulnerability, vulnerable group & 85 \\
\hline
\end{tabular}

Word counts from the NLP classified entities related to conflict in GEF Climate Change projects are presented in Table 2. Simple word counts results of the NLP classification follow a similar pattern as phrase entities, but the direct impact of conflict associated with increasing risk in general implications for security are most frequent. There are concerns about conflict and associations with vulnerability. Taken together, the results indicate conflict related issues are generally associated with political instability or insecurity.

Table 2. Words frequently associated with conflict in climate change project evaluations resulting from NLP analysis.

\begin{tabular}{cc}
\hline Words Associated with Conflict & $\begin{array}{c}\text { Frequency } \\
\text { (\# of Occurrence in Evaluations) }\end{array}$ \\
\hline risks & 315 \\
security & 291 \\
vulnerability & 286 \\
political & 261 \\
issues & 242 \\
\hline
\end{tabular}

There were 909 terminal evaluation related documents coded as Biodiversity projects. The machine learning NLP classifier produced a different set of text entities associated with conflict from these project terminal evaluation reports. The entities are presented in a worldcloud graphic where the size of the word represents its relative frequency in Figure 5. Again, the word crisis is central and captures the overall context of insecurity and increased security risks. Poverty is the most prominent social condition associated with conflict. Biodiversity projects often include an aspect of defining a protected area, sanctuary or park to regulate access and use. The wordcloud reflects how the dynamics of conflict are associated with land, forest, mining and other areas of natural resources. Killing, hunting, illegal activities and violence are also associated with conflict in these projects, though somewhat less prominently. Similarly, armed groups, civil war, global, regional and ethnic appear in the NLP classifier results from biodiversity project evaluations. Diseases including Ebola are prominent in Biodiversity project documentation, while disasters are relatively less frequently associated with these projects compared to the Climate Change project documents.

A diverse set of phrases associated with conflict were extracted by the NLP machine learning classifier for the GEF biodiversity project terminal evaluations and are presented in Table 3. Poverty particularly in rural areas and poverty associated with the overall economic situation are the most frequent phrases associated with conflict. Armed and 
violent conflict associated with war, insecurity and post conflict contexts are also prevalent in the text entities extracted by the classifier. This is related to the frequent identification of the military from the texts. Political unrest, turmoil and crisis also occur frequently. The classic focuses of reducing conflict between humans and animals as well as reducing conflict associated with land tenure were also identified by the classifier.

Table 3. Phrases frequently associated with conflict in biodiversity project evaluations.

\begin{tabular}{|c|c|c|}
\hline \multicolumn{3}{|c|}{ NLP Results of GEF Biodiversity Terminal Evaluations } \\
\hline & $\begin{array}{c}\text { Frequent Phrases Associated } \\
\text { with Conflict }\end{array}$ & $\begin{array}{c}\text { Frequency } \\
\text { (\# of Occurrence in } \\
\text { Evaluations) }\end{array}$ \\
\hline \multirow[t]{2}{*}{$\begin{array}{l}\text { Human Security Threats } \\
\text { (elements related to conflict) }\end{array}$} & $\begin{array}{c}\text { poverty, rural poverty, } \\
\text { poverty reduction, } \\
\text { economic/ financial crisis }\end{array}$ & 81 \\
\hline & $\begin{array}{c}\text { land tenure, land conflict, land } \\
\text { use conflict }\end{array}$ & 17 \\
\hline \multirow[t]{3}{*}{$\begin{array}{c}\text { Resilience Disenablers } \\
\text { (elements related to conflict) }\end{array}$} & $\begin{array}{l}\text { civil war, war, security } \\
\text { situation, security } \\
\text { problems/issues/concerns, } \\
\text { post conflict }\end{array}$ & 77 \\
\hline & $\begin{array}{l}\text { political crisis, political } \\
\text { turmoil, political unrest }\end{array}$ & 76 \\
\hline & military groups, military coup & 20 \\
\hline $\begin{array}{l}\text { Environmental Security Threats } \\
\text { (elements related to conflict) }\end{array}$ & $\begin{array}{l}\text { human wildlife conflict, } \\
\text { human elephant }\end{array}$ & 31 \\
\hline
\end{tabular}

Word counts taken from the NLP extracted text entities associated with conflict demonstrate the close association of poverty and conflict (see Table 4). Uncertain land and livelihood security may have negative feedback with the observed political nature of conflict in these Biodiversity project areas. The conflict contexts are associated with the text entities that are descriptive of an insecure situation, with frequent threats and an atmosphere of instability and crisis. At least some of the contexts include armed conflict that is identified by the frequency of words like war, military and civil. As with Climate Change projects, we again see the association of poverty and fire in the word frequency counts for text entities associated with conflict in GEF Biodiversity projects.

Table 4. Words frequently associated with conflict in biodiversity project evaluations resulting from NLP analysis.

\begin{tabular}{cc}
\hline Words Associated with Conflict & $\begin{array}{c}\text { Frequency } \\
\text { (\# of Occurrence in Evaluations) }\end{array}$ \\
\hline political & 108 \\
security & 98 \\
threat/threats & 91 \\
crisis & 74 \\
poverty & 58 \\
fire/fires & 54 \\
instability & 37 \\
civil & 36 \\
military & 33 \\
war & 30 \\
\hline
\end{tabular}

\subsection{Case Examples}

Thirty-five case summaries and coding templates were used for training the machine learning NLP classifier. Here, we present one case summary of a GEF Climate Change 
project and one case summary of a GEF Biodiversity project to illustrate the types of conflict associations that the NLP classifier identified from more than 1500 GEF project terminal evaluation documents.

4.3.1. Climate Change Project in a Complex Emergency-When Natural Disaster and Conflict Impact Environmental Projects: Niger Sustainable Co-Management of the Natural Resources of the Air-Ténéré Complex

Emergency programs that include large transfers such as food aid can have disruptive effects on local markets and rural development [70], but less is known about how they affect integrated environmental protection projects. In Niger, from 2006 to 2012, GEF and UNDP partnered to implement the Sustainable Co-Management of the Natural Resources of the Air-Ténéré Complex project. The project goals included improved governance through representative land commissions, food and water security projects, and conservation of an existing designated protected area. Armed conflict erupted between the Tuareg ethnic group and the Government during the project that precipitated emergency food programs and significantly increased project costs. The increased costs for hiring vehicles and transportation resulted in a scaling back of project activities. Cooperatives, supported as part of the project design, reported competition and low prices for their production because of an oversupply of free emergency food. These free distributions ultimately led to failure of the longer-term food security related activities promoted by the GEF project. There continued to be a difficulty communicating the connection between project activities and the project goals with stakeholders. Ultimately, the evaluators questioned the sustainability of the environmental protection, governance and security projects in the face of weak institutions and conflict.

4.3.2. Biodiversity in Fragile Contexts-Insecurity, Small Arms and Incentives for Project Stakeholders: Cambodia Cardamom Mountains Protected Forest and Wildlife Sanctuaries Project

Biodiversity projects face challenges from illegal trade in contraband, often exacerbated by the availability of small arms and weak institutions. The contraband often consists of, or comes from, the very species that owe their existence to the protections afforded by designated conservation or preservation areas [71]. In this way, protected areas may serve to foster resource abundance, leading to greater availability and increased trafficking, or they may highlight the location of otherwise scarce resources that become valuable as a result of increased demand. From 2002 to 2007, the biodiversity-focused Cardamom Mountains Protected Forest and Wildlife Sanctuaries Project was implemented in Cambodia. The objective of the project was to develop a long-term conservation framework for a protected area with associated buffer zones, to be secured in part through World Heritage designation for the area. The project took place in a former Khmer Rouge stronghold with weak local institutions and daily conflicts over land clearing and land sales/transfers. In addition to the legal framework, the project focused on building the local protected area capacity and engaging the community. Illegal resource extraction, particularly the contraband substance used to make the illegal recreational pharmaceutical methylenedioxymethamphetamine from Mreah Prew Phnom trees (Cinnamomum parathenoxylon), was commonplace. Rivalry for control of the profits from contraband between local authorities, the military and illegal gangs led to regular conflict and general insecurity. Furthermore, assessments for the project proposal identified the military and local police as primary sources of small arms for rent or sale that were used in poaching and other illegal activities. The project was delayed and activities canceled because of security incidents. After two park rangers were murdered, patrol activities in the protected area were suspended.

\subsection{Thematic Summaries of GEF Projects in Conflict-Affected Areas Selected for Review}

Here, we present the results of three thematic summaries of the coding templates used on 35 case summaries to provide context to the types of conflict associations that the NLP classifier identified from more than $1500 \mathrm{GEF}$ project terminal evaluation documents. 


\subsubsection{Resilience Outcomes Pursued in Selected GEF Projects}

Across GEF projects reviewed, promoting resilience outcomes commonly included a focus on governance, participation, and effective conflict resolution as indicated in Figure 5. Land tenure security as well as other programming aimed at securing rights to fishing or other use of common resources played a role in many GEF projects. Building consensus around conservation priorities and negotiating just distribution of and access to common resources was the crux of stakeholder engagement for integrated environmental protection projects. Supporting governance structures that are inclusive and credible was crucial to the success and sustainability of the projects. Inequity in the community was often mirrored in the formal and informal governance structure of project areas. Therefore, integrated environmental protection projects tended to begin with, and their ultimate success depended on, facing challenges of marginalization, vulnerability and inequity.

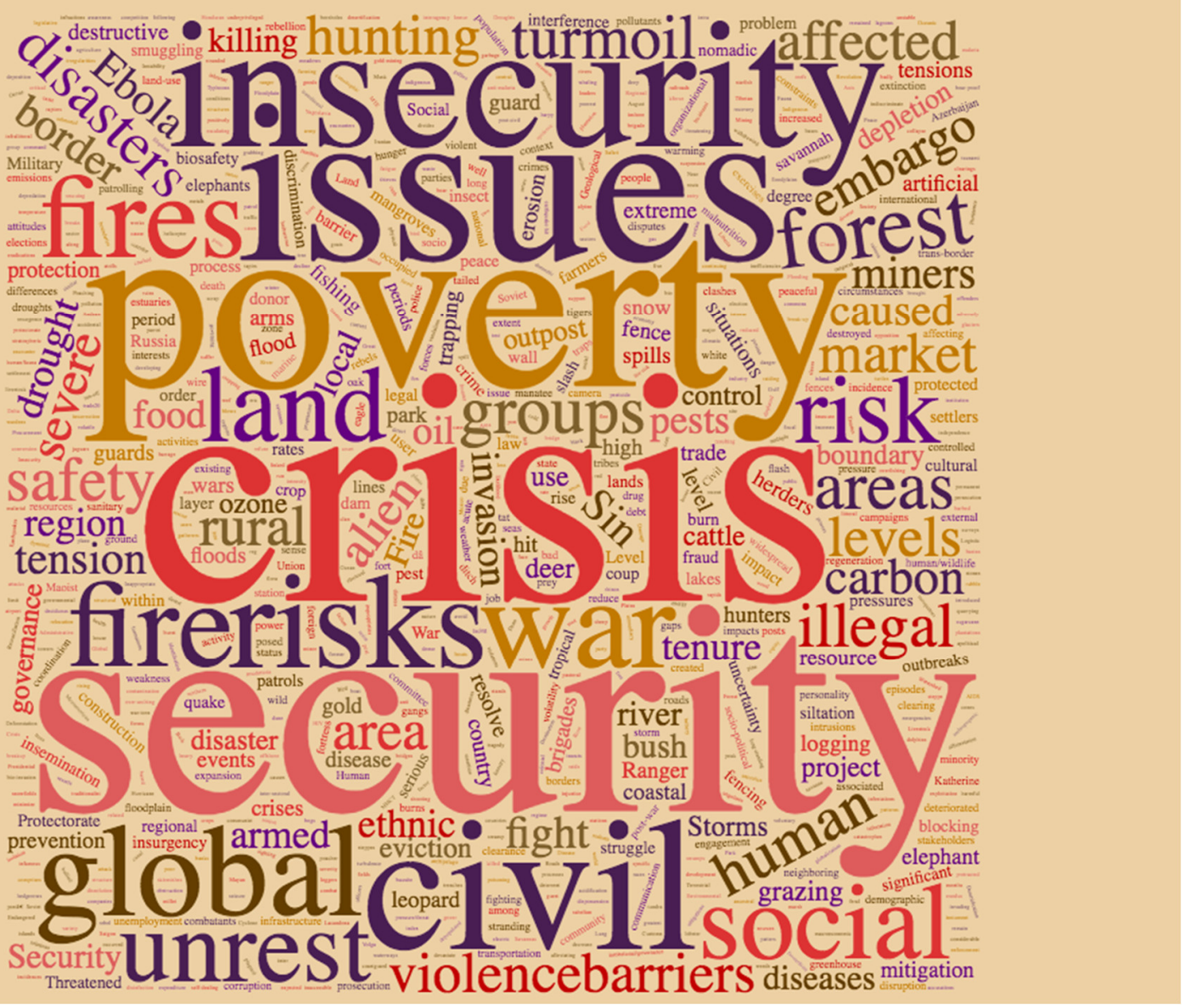

Figure 5. Wordcloud graphic produced from text entities associated with conflict in GEF biodiversity project terminal evaluations.

Examples of improved cooperation between rival armed groups due to GEF governanceoriented project activities were reported in Macedonia and the Philippines. In Macedonia, the project included stakeholders from two "warring ethnic groups" and the evaluation noted "the two towns were in different ethnic areas but in spite of the turbulence they worked together with the [Project Implementation Unit] to get the project done". In the Philippines, the GEF Project Implementation Unit was seen as neutral and as an "honest broker" between rebel groups and the Government. GEF projects, including one in Colombia, intentionally incorporated empowerment-focused inclusion of vulnerable stakeholders that had disproportionately suffered violence during conflict, such as indigenous people and women. 
Conflict resolution featured prominently in protected area biodiversity projects and integrated agro-ecosystem management approaches to address land degradation. In Niger, 14 different local organizations such as Land Commissions were established and supported with training to alleviate resource-based conflict in the program area. Biodiversity programs also trained protected area committees in conflict resolution and, to some extent, trained broader stakeholders. In the Colombia case, six partners in a sub-national environmental protection committee were trained at the local level and four at the headquarters level. In the second phase of a sustainable land use project in Senegal, lessons learned from the previous project phase on institutional stakeholder conflicts were integrated into the design.

\subsubsection{Human Security Outcomes Linked in GEF Projects Selected for Review}

Human security objectives are promoted with other environmental protection objectives in all of the GEF projects selected for review. A common project logic is evident where protection for the environment is furthered when vulnerable people are also protected by ensuring basic needs along the lines of the seven elements of human security described by UNDP (1994); Economic, Food, Health, Environmental, Personal, Community, Political Security [21]. Often these security ideas were translated into GEF programs along sectoral lines such as Water, Energy and Livelihood Security as indicated in Figure 6. Perhaps due to the conflict context and high vulnerability of the project sites, human security objectives were prominent in all of the GEF projects selected for review. Food (44\%) and water (44\%) security were the most common human security-related outcomes in nearly half of all the projects reviewed as seen in Figure 7. Activities associated with these outcomes included climate smart agriculture or watershed and water source rehabilitation. Comprehensive livelihood security (25\%) projects that focus on improved technology or generating new sources of income were somewhat less common. Although energy security (19\%) projects were some of the most successful projects in terms of participant satisfaction and conflict resolution outcomes, this outcome was relatively less of a focus in the projects reviewed.

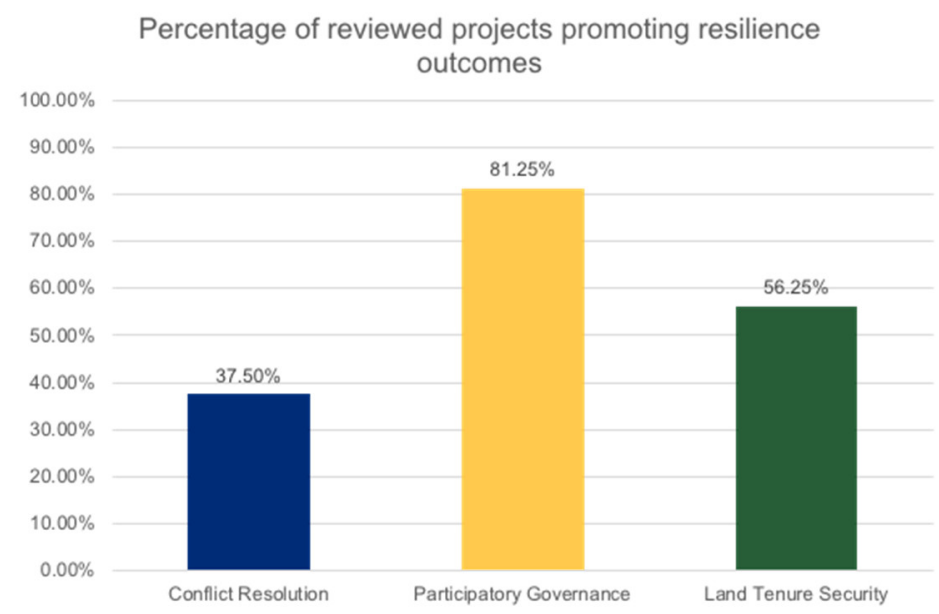

Figure 6. Percentage of projects reviewed by this paper's authors promoting common resilience objectives.

4.4.3. Destabilized Weak Institutions and General Insecurity Undermine Environmental Security Efforts in Conflict-Affected Areas

Project evaluations from across the globe reported delayed implementation and other programming issues in conflict-affected areas such as in the Philippines, Yemen, Cambodia, Nepal, Pakistan and Niger. Destabilization of host national systems and institutions and insecurity undermined the key approaches to strengthening sustainable pathways to ensure environmental protection and resilience. Limited access to project areas, difficulties recruiting staff, reallocation by host governments of funds or resources, and supply chain interruptions were cited as causes for the delays. Where national government partners are not available, reliable counterparts and stakeholders become critical to carrying out 
protection activities. In the course of engaging in project activities, negotiators may be required to interact with groups that may or may not be accountable to local populations and unsuccessful collaboration can result in project sites being cancelled or moved. For example, projects were adversely affected due to rebel group activities in the project areas in Nepal and the Philippines, uncooperative counterparts in Yemen and Nepal, or generalized insecurity in the Pakistan case.

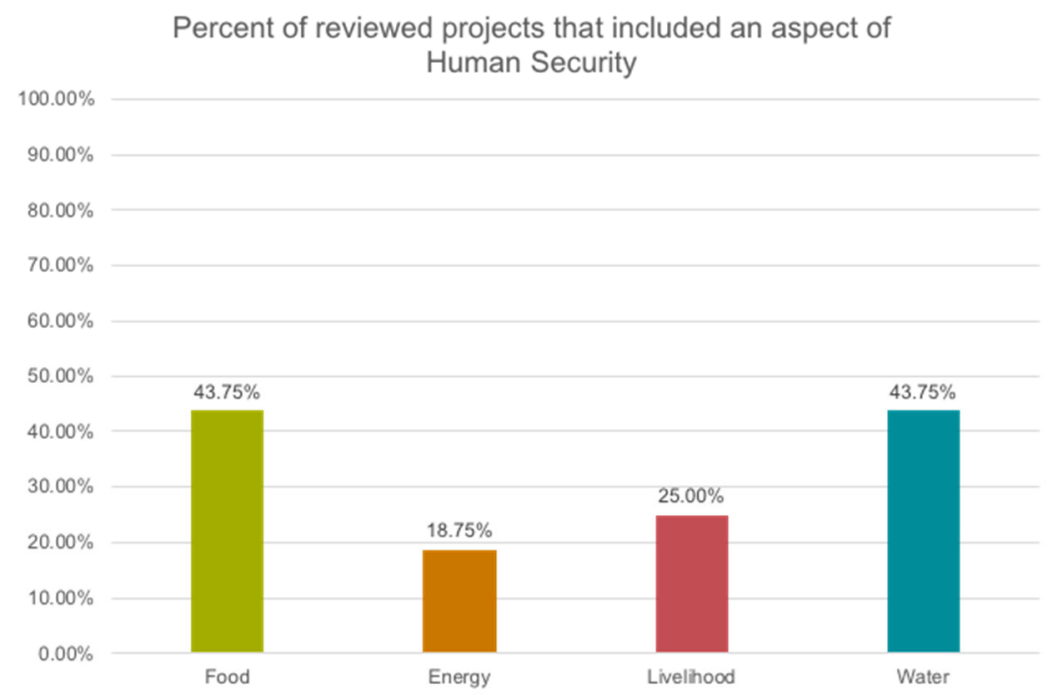

Figure 7. Percentage of projects reviewed by this paper's authors including an aspect of human security.

Insecurity undermines the social norms and rule of law that is the foundation of environmental protection and ultimately human security. The GEF case summaries noted the direct effects of insecurity. Stakeholders and project managers were threatened and moved in the Philippines, Yemen, Cambodia and Nepal. Project and personal equipment was confiscated in the Philippines but was also a concern in other projects. Deaths were reported in two GEF biodiversity projects selected for analysis-one in Cambodia and one in Colombia, where park administrators and rangers were murdered while serving to protect threatened areas, flora and fauna. In Colombia, indigenous stakeholders participating in project activities were also killed or the targets of violence. Contraband traffic, weak government institutions and a proliferation of arms contributed to the extreme insecurity that produced the tragic conditions where these events took place.

\section{Discussion}

Co-location of environmental protection projects and ongoing violent conflict is confirmed in geo-spatial analysis of the GEF portfolio. This is highly consistent with other research on conflict and the environment. We find that seventy-three percent of the geolocated GEF land degradation projects in Africa are near to violent conflict events. Other researchers have estimated eighty-percent of global biodiversity hotspots are conflictaffected [72,73]. Some patterns relating spatial correlation of armed conflict and poor environmental outcomes are increasingly clear. For example, large mammals, followed by small mammals, are at greatest risk of biodiversity loss as small arms proliferate during active conflicts [74] and species protection is difficult and dangerous. Deforestation is reported to more likely occur after periods of frequent skirmishes because trees exploited for timber are no longer protected from loggers who were afraid to enter areas undergoing active fighting [75]. Information available from the GEF database and the analytical case studies presented in the results provide rich detail to highlight emerging patterns. The case report from Cambodia describes illegally 'hunted' Mreah Prew Phnom in areas of extreme insecurity. In this case, the rangers who were murdered while protecting the trees faced the same programmatic challenges and physical danger more frequently associated with projects designed to protect animal biodiversity by reducing illegal poaching [76]. 
The co-location of climate-change related environmental degradation, vulnerability to extreme weather events, and conflict was also consistently reported in the GEF program documents and confirmed in the geo-spatial analysis. In the case study from Niger, efforts to restore resilience and food security to conflict-affected communities facing desertification focused in large part on improved land management and governance. During project implementation, the intensification of intercommunity conflict set in motion a series of programmatic setbacks that undermined achievement of longer-term resilience and food security goals.

Older literature focusing on a simple theory of resource scarcity and environmental degradation leading to conflict as proposed by Homer-Dixon [51,77] does not provide a compelling explanation of the case study dynamics. Instead, more recent literature finding the direct statistical links between climate change and conflict outcomes are highly location-dependent and highlights the conflict risks associated with implementing climate adaption and mitigation strategies [78]. The GEF Niger projects illustrates this point-the impact on local markets and agricultural production from the food aid-focused emergency response was cited as the cause of the environmental protection project failure. A review of the last decade of literature connecting climate change and conflict finds the results to be inconclusive. Authors suggest the future research focus on the political and socio-economic situation and the human security outcomes that are likely to reveal the causal connections relating conflict and environmental degradation [79].

Applying the Protective Pathways conceptual frame to our NLP results shows that resilience related concerns about political instability and gender inequality are most associated with conflict in GEF Climate Change related projects. Extreme weather events and disasters also are slightly more frequently associated with conflict in these projects. This result is consistent with the work of Brzoska (2018) [80], which finds that it is the disaster associated with extreme events that often link negative conflict and climate change outcomes. Human security issues of food insecurity, vulnerability and poverty are also related to conflict in the GEF Climate Change project evaluations. The NLP entity identification does not allow for determination of causal relationship. Nonetheless, the conflict word associations described in this paper support adoption of a resilience logic in the structure of protective pathways that includes approaches to manage risk, ensure security, reduce vulnerability and resolve political issues. At minimum, in projects located near active conflict these resilience and governance concerns should be addressed to advance desired human and environmental security outcomes.

For GEF Biodiversity projects located in conflict-affected areas, human security related issues of poverty and livelihood security related to land use and land tenure were dominant in the NLP results. Weak institutions have been identified in spatial analysis as a primary condition for localized poverty and correlate strongly with localized violent conflict [81]. Although Gaynor et al., (2016) [82] identified many pathways to biodiversity loss during armed conflict, weakening of local institutions consistently led to negative impacts on wildlife populations. Similarly, in our analysis of the GEF Biodiversity projects the NLP results highlighting turmoil, crisis and unrest related to conflict speak to how resilience and governance is undermined by the atmosphere of violence and impunity. In what can be described as a variation in the 'resource curse' for biodiversity hotspots, high-value flora and fauna exploited in conflict can lead to a wide range of negative outcomes such as emboldening criminal networks and undermining local institutions [83]. Targeting and destroying traditional or culturally important trees, animals and sacred wilderness spaces can be intentional tactics of grievance-based violence. Biodiversity project conflictrelated NLP word entities reinforce the security and resilience dimensions of environmental protection problems and the need to address them.

A vicious circle of systematic feedbacks is how Buhaug and Uexkull (2021) [84] describe the relationship of human security drivers of vulnerability to conflict and of vulnerability to negative impacts of climate change. GEF projects frequently employed interventions intended to build the resilience of local governance and institutions to disrupt 
the negative cycle and reduce vulnerability. For example, four-out-of-five projects pursued participatory governance outcomes and over one-half of GEF-funded interventions involved promoted land tenure. Meta-analysis of projects designed to secure land use rights report clear, positive impacts of improved governance with environmental protection and human wellbeing [85]. Notably, although the GEF projects were located in conflict-affected areas, less than one-third had specific programming for conflict resolution. Some project documents noted that the maintenance of neutrality was an unstated goal of the project that prevented directly intervening in conflict reduction. Human security programming in the thirty-five GEF project reviewed most frequently focused on water and food security. In contrast to the NLP analysis highlighting the importance of poverty and inequality to conflict, only one-quarter of reviewed cases had a strong focus on livelihood security. Even fewer focused on energy security despite the clear links to negative impacts of energy poverty and the environment.

Implicit in the results of NLP-assisted content and spatial analysis of the GEF Climate Change and Biodiversity projects is that resilience strengthening and ensuring human security are the foundation for successfully attaining environmental protection goals. The protective pathways conceptual frame highlighting key relationships at the nexus of environmental protection, human security and resilience programming captures many of the dynamics observed in GEF projects in conflict affected-areas. Emerging literature is establishing the poverty reduction and livelihood security benefits associated with improving environmental quality [86]. At the same time, researchers are beginning to explore a wider range of co-benefits of interventions focused at improving environmental quality and this includes the environmental peace building potential of climate mitigations projects [87] and climate adaptation policy implementation [88]. As interest in synergies between environmental and humanitarian concerns converge under a new umbrella term of climate security, there is acknowledgement that research has been more adept at identifying associations of risks and more research is necessary on applied questions of what we need to know for successful policy implementation particularly in conflict affected countries with weak institutions [89].

Novel data sets and innovative methods such as NLP and spatial analysis may be required to provide fresh explanatory perspectives on observed statistical associations between conflict and undesirable environmental and wellbeing outcomes. Mixed method research requires conceptual frames in addition to statistical models to effectively integrate data and analysis from a variety of sources. The protective pathways model can become more complete, accurate in identifying key relationships and practical for application in policy design and implementation through additional research. Initial use of NLP for identifying textual entity associations is encouraging but more sophisticated machine learning and modelling may give greater insight into causal relations observed. Much of this relies on solving problems of data scarcity, which is a longstanding issue in conflict research.

Limitations to this study include a limited amount of geolocation information for GEF projects to use in spatial analysis. Coding of conflict events also had a limitation in the years of coverage at more local levels and the level of spatial accuracy sometimes limited to the nearest named place rather than a specific event location. Although NLP is a tool for unstructured data, GEF evaluations had a high degree of variability in structure, terminology and criteria. Environmental security and conflict were rarely explicitly and formally examined as evaluation questions. The Google NLP API is better suited to tackling inconsistent data sources and lower quality data; however, it is a paid service and only limited training and testing of the models was possible due to cost considerations.

Further research in machine learning approaches to classifying entities and sentiments from unstructured text data can be expanded to look at a wider range of concepts such as gender, participation, resilience and sustainability. The possibilities are wide open if the funding, or perhaps open source machine learning for NLP, becomes available. Particularly interesting is the integration of geospatial location information with machine learning for 
increasingly local insights into environmental and social factors at more granular local levels and among key networks.6. Conclusions

Protecting the environment successfully in conflicted-affected areas is associated with ensuring adequate safeguards for people and strengthening local institutions. Active armed conflict often occurs in remote and marginal areas that are also the geographic focus of environmental protection projects. Across contexts and different types of conflict, previous studies relying on linear statistical associations do not consistently predict the strength or even the direction of key policy relevant indicators with environmental degradation or extreme events linked to climate change. At the same time, not taking conflict into consideration in environmental protection project design or implementation resulted in delays and failure to achieve desired outcomes.

A conceptual framing of the protective pathways linking environmental protection, human security and the system strengthening actions that enable resilience was developed to support mixed-method analysis. A novel data source of 1500 GEF project documents was interrogated in a three-step investigation. After confirming that at least one-third of GEF projects had taken place in conflict-affected countries, geospatial analysis was conducted to assess how many projects were implemented near active armed conflict. Existing geolocation information for projects and conflict event data for Africa confirmed that more $73.00 \%$ of GEF projects were implemented in the same districts where conflict was active during the life of the project. Content analysis for 1500 project evaluations from conflict-affected countries were then analyzed for text entities related to conflict using Google's NLP machine learning algorithm. The protective pathways concept frame was used for classification and reflection on the extracted phrases and words. Thirty-five indepth case studies were then created from available GEF documentation to identify the sequence of events, key relationships and impact of conflict with program approaches and outcomes.

Biodiversity projects most frequently associated poverty and livelihood security to conflict. Crisis, open warfare and an atmosphere of impunity created by non-existent or weak local institutions led to extremely poor project outcomes including the deaths of park rangers. Climate change projects associated political crisis and gender inequality with conflict. Active fighting indirectly undermined environmental outcomes aimed at more participatory governance and strengthening of food systems in the Niger case study. Rather than conflict directly damaging the environment or project implementation, the response to the humanitarian crisis and to the conflict, including food aid, disrupted the longer-term interventions. Improving participatory governance and strengthening local institutions were identified as essential programming approaches across different environmental projects in conflict affected contexts. The protective pathways framing of key relationships of security and resilience enabling capacities proved useful in understanding the impacts and outcomes of environmental protection projects in these vulnerable areas.

The evidence base for policy discussions and policy implementation approaches to complex threats to human and planetary wellbeing requires more than is often offered by reductionist associations. Actionable guidance for local interventions requires conceptualization of key causal relations behind desirable environmental protection and human security outcomes that is informed by practice in real world environments. Although they are not experiments, projects have a hypothesis behind their implementation and outcomes that can be interrogated. In this process, resilient, polycentric and participatory governance is key. These unstructured project data are difficult to analyze efficiently, but new tools such as NLP and increased availability of geocoded data allow new possibilities for investigating a wider variety of variables and contexts. This study is a promising proof-of-concept for using programmatic documentation as a novel big data source for testing interesting emergent theories on the relation of conflict, security and resilience. Automated geocoding and technological innovation in working with extremely unstructured data promise better future evidence to understand interlinked environmental and human security challenges and to develop effective interventions with actionable guidance. 


\begin{abstract}
Author Contributions: Conceptualization, N.M. and N.B.M.; methodology, N.M.; software, N.M.; validation, N.M., A.G. and N.B.M.; formal analysis, N.M.; investigation, N.M., M.H. and J.L.; resources, N.M.; data curation, N.M. and M.H.; writing-original draft preparation, N.M. and J.L.; writing-review and editing, N.M., A.G. and J.L.; visualization, N.M. and M.H.; supervision, N.M.; project administration, N.M.; funding acquisition, N.M. All authors have read and agreed to the published version of the manuscript.

Funding: UNOPS released a 10,000 USD request for proposals in 2017 to support the Global Environment Facility (GEF) in geospatial analysis of projects in conflict affected areas. Nathan Morrow was competitively selected and submitted a technical report later that year to GEF. The report was submitted to the GEF Scientific and Technical Advisory Panel in support of their preparation for programme guidance for the $7 \mathrm{th}$-replenishment process. The geospatial analysis was undertaken with these resources. Subsequent NLP, content analysis and case summary were undertaken without specific funding.
\end{abstract}

Data Availability Statement: All data is publically available at the website locations indicated in the reference section.

Acknowledgments: We would like to share our appreciation for the Global Environment Facility's commitment to transparency by sharing project documents and evaluations openly in an on-line database. N.M. would like to thank Virginia Gorevsky and STAP for their work on environmental security and feedback on his unpublished report. We would also like to thank Google for providing a limited free trial to use the NLP API on our dataset. Also, appreciation to the open source development community that supports QGIS.

Conflicts of Interest: There are no conflicts of interest.

\title{
References
}

1. Kremen, C.; Merenlender, A.M. Landscapes that work for biodiversity and people. Science 2018, 362, eaau6020. [CrossRef] [PubMed]

2. $\quad$ Barnard, P.; Moomaw, W.R.; Fioramonti, L.; Laurance, W.F.; Mahmoud, M.I.; O'Sullivan, J.; Rapley, C.G.; Rees, W.E.; Rhodes, C.J.; Ripple, W.J.; et al. World scientists' warnings into action, local to global. Sci. Prog. 2021, 104, 1-32. [CrossRef] [PubMed]

3. FAO; IFAD; UNICEF; WFP; WHO. The State of Food Security and Nutrition in the World 2021. Transforming Food Systems for Food Security, Improved Nutrition and Affordable Healthy Diets for All; FAO: Rome, Italy, 2021. [CrossRef]

4. Udmale, P.; Pal, I.; Szabo, S.; Pramanik, M.; Large, A. Global food security in the context of COVID-19: A scenario-based ex-ploratory analysis. Prog. Disaster Sci. 2020, 7, 100120. [CrossRef]

5. Strand, H.; Hegre, H. Trends in Armed Conflict, 1946-2020, Conflict Trends, 3; PRIO: Oslo, Norway, 2021.

6. Shukla, P.; Skea, J.; Calvo Buendia, E.; Masson-Delmotte, V.; Pörtner, H.; Roberts, D.; Zhai, P.; Slade, R.; Connors, S.; Van Diemen, R.; et al. Climate Change and Land: An IPCC Special Report on Climate Change, Desertification, Land Degradation, Sustainable Land Management, Food Security, and Greenhouse Gas Fluxes in Terrestrial Ecosystems; IPCC: Geneva, Switzerland, 2019. (in press)

7. Anderson, W.; Taylor, C.; McDermid, S.; Ilboudo-Nébié, E.; Seager, R.; Schlenker, W.; Cottier, F.; de Sherbinin, A.; Mendeloff, D.; Markey, K. Violent conflict exacerbated drought-related food insecurity between 2009 and 2019 in sub-Saharan Africa. Nat. Food 2021, 2, 603-615. [CrossRef]

8. Chapin, F.S.; Díaz, S. Interactions between changing climate and biodiversity: Shaping humanity's future. Proc. Natl. Acad. Sci. USA 2020, 117, 6295-6296. [CrossRef] [PubMed]

9. Roberts, E.; Pelling, M. Loss and damage: An opportunity for transformation? Clim. Policy 2019, 20, 758-771. [CrossRef]

10. Mori, A.S. Advancing nature-based approaches to address the biodiversity and climate emergency. Ecol. Lett. 2020, 23, 1729-1732. [CrossRef]

11. Habibullah, M.S.; Din, B.H.; Tan, S.-H.; Zahid, H. Impact of climate change on biodiversity loss: Global evidence. Environ. Sci. Pollut. Res. 2021, 1-14. [CrossRef]

12. Pettorelli, N.; Graham, N.A.J.; Seddon, N.; Bustamante, M.M.D.C.; Lowton, M.J.; Sutherland, W.J.; Koldewey, H.J.; Prentice, H.C.; Barlow, J. Time to integrate global climate change and biodiversity science-policy agendas. J. Appl. Ecol. 2021, 58, $2384-2393$. [CrossRef]

13. Ratner, B.D.; Meinzen-Dick, R.; May, C.; Haglund, E. Resource Conflict, Collective Action, and Resilience: An Analytical Framework. Int. J. Commons 2013, 7, 183-208. [CrossRef]

14. Morrow, N.; Hudson, M. Assessing the Relationship between Armed Conflict and the Global Environment Facility from 1992 to 2016. GEF STAP Technical Report; Technical Report; GEF STAP: Washington, DC, USA, 2017.

15. UNDP. Climate Finance for Sustaining Peace: Making Climate Finance Work for Conflict Affected and Fragile Contexts; UNDP: New York, NY, USA, 2021.

16. Schilling, J.; Nash, S.L.; Ide, T.; Scheffran, J.; Froese, R.; von Prondzinski, P. Resilience and Environmental Security: Towards Joint Application in Peacebuilding. Glob. Chang. Peace Secur. 2017, 29, 107-127. [CrossRef] 
17. Dabelko, G.D.; Dabelko, D.D. Environmental Security: Issues of Conflict and Redefinition. Environ. Chang. Secur. Proj. Report 1995, 1, 3-13.

18. Trombetta, M.J. Environmental Security and Climate Change: Analysing the Discourse. Camb. Rev. Int. Aff. 2008, 21, 585-602. [CrossRef]

19. World Commission on Environment and Development. Our Common Future; Oxford University Press: New York, NY, USA, 1987.

20. Hughes, H. Ch 4Envtl Sec in Global Environmental Politics Concepts, Theories and Case Studies, 2nd ed.; Imprint Routledge: London, UK, 2018.

21. UNDP. Human Development Report 1994; UNDP: New York, NY, USA, 1994; ISBN 0-19-509170-1.

22. Bierbaum, R.; Stocking, M.; Bouwman, H.; Cowie, A.; Diaz, S.; Granit, J.; Patwardhan, A.; Sims, R.; Duron, G.; Gorsevski, V.; et al. Delivering Global Environmental Benefits for Sustainable Development. Report of the Scientific and Technical Advisory Panel (STAP) to the 5th GEF Assembly, México 2014; Global Environment Facility: Washington, DC, USA, 2014.

23. Gatto, A. A pluralistic approach to economic and business sustainability: A critical meta-synthesis of foundations, metrics, and evidence of human and local development. Corp. Soc. Responsib. Environ. Manag. 2020, 27, 1525-1539. [CrossRef]

24. O'Brien, K.; Sygna, L.; Wolf, J. A changing environment for human security. In A Changing Environment for Human Security; Routledge: London, UK; New York, NY, USA, 2013; pp. 27-50.

25. O'Brien, K. Global Environmental Change II: From Adaptation to Deliberate Transformation. Prog. Hum. Geogr. 2012, 36, 667-676. [CrossRef]

26. O'Brien, K. Are we missing the point? Global environmental change as an issue of human security. Glob. Environ. Chang. 2005, 16, 1-3. [CrossRef]

27. Sadik-Zada, E.R. Distributional Bargaining and the Speed of Structural Change in the Petroleum Exporting Labor Surplus Economies. Eur. J. Dev. Res. 2020, 32, 51-98. [CrossRef]

28. Sadik-Zada, E.R. Natural resources, technological progress, and economic modernization. Rev. Dev. Econ. 2021, 25, 381-404. [CrossRef]

29. Martin, A.; Blowers, A.; Boersema, J. Is environmental scarcity a cause of civil wars? Environ. Sci. 2006, 3, 1-4. [CrossRef]

30. Bannon, I.; Collier, P. Natural Resources and Violent Conflict: Options and Actions; The World Bank: Washington, DC, USA, 2003.

31. Barnett, J. The Meaning of Environmental Security: Ecological Politics and Policy in the New Security Era; Zed Books: London, UK; New York, NY, USA, 2001.

32. Homer-Dixon, T.F. Environmental Scarcities and Violent Conflict: Evidence from Cases. Int. Secur. 1994, 19, 5-40. [CrossRef]

33. Barnett, J.; Adger, W.N. Climate Change, Human Security and Violent Conflict. Political Geogr. 2007, 26, 639-655. [CrossRef]

34. Ide, T.; Scheffran, J. On climate, conflict and cumulation: Suggestions for integrative cumulation of knowledge in the research on climate change and violent conflict. Glob. Chang. Peace Secur. 2014, 26, 263-279. [CrossRef]

35. Lukas, K.; Rüttinger, L. Insurgency, Terrorism and Organised Crime in a Warming Climate: Analysing the Links Between Climate Change and Non-State Armed Groups; Adelphi: Berlin, German, 2016.

36. United Nations General Assembly. General Assembly Declaration on the Strengthening of International Security; UN General Assembly: New York, NY, USA, 1970.

37. Resilience Measurement Working Group. Resilience Measurement; FAO: Rome, Italy, 2021.

38. Gatto, A.; Drago, C. Measuring and modeling energy resilience. Ecol. Econ. 2020, 172, 106527. [CrossRef]

39. Norris, F.H.; Stevens, S.P.; Pfefferbaum, B.; Wyche, K.F.; Pfefferbaum, R.L. Community Resilience as a Metaphor, Theory, Set of Capacities, and Strategy for Disaster Readiness. Am. J. Community Psychol. 2008, 41, 127-150. [CrossRef]

40. Manyena, S.B. The concept of resilience revisited. Disasters 2006, 30, 434-450. [CrossRef] [PubMed]

41. Armitage, D.; Béné, C.; Charles, A.; Johnson, D.; Allison, E. The Interplay of Well-Being and Resilience in Applying a SocialEcological Perspective. Ecol. Soc. 2012, 17. [CrossRef]

42. Berkes, F. Understanding uncertainty and reducing vulnerability: Lessons from resilience thinking. Nat. Hazards 2007, 41, 283-295. [CrossRef]

43. Gatto, A. Polycentric and resilient approaches for governing the commons: Strategic and legal insights for sustainable development. Ambio 2022.

44. Bahadur, A.V.; Ibrahim, M.; Tanner, T. The Resilience Renaissance? Unpacking of Resilience for Tackling Climate Change and Disaster; Strengthening Climate Resilience Discussion Paper 1; Institute of Development Studies: Brighton, UK, 2010.

45. Berkes, F.; Ross, H. Community Resilience: Toward an Integrated Approach. Soc. Nat. Resour. 2013, 26, 5-20. [CrossRef]

46. Holling, C.S. Resilience and Stability of Ecological Systems. Annu. Rev. Ecol. Syst. 1973, 4, 1-23. [CrossRef]

47. Walker, B.H.; Ludwig, D.; Holling, C.S.; Peterman, R.M. Stability of Semi-Arid Savanna Grazing Systems. J. Ecol. 1981, 69, 473. [CrossRef]

48. Folke, C. Resilience: The emergence of a perspective for social-ecological systems analyses. Glob. Environ. Chang. 2006, 16, 253-267. [CrossRef]

49. Gunderson, L.H.; Allen, C.R.; Holling, C.S. Foundations of Ecological Resilience; Island Press: Washington, DC, USA, 2012.

50. Oels, A. From 'Securitization' of Climate Change to 'climatization 'of the Security Field: Comparing three theoretical perspectives. In Climate Change, Human Security and Violent Conflict; Springer: Berlin/Heidelberg, Germany, 2012; pp. 185-205.

51. Homer-Dixon, T.F. On the Threshold: Environmental Changes as Causes of Acute Conflict. Int. Secur. 1991, 16, 76. [CrossRef]

52. Meadows, D.; Randers, J. The Limits to Growth: The 30-Year Update; Routledge: London, UK, 2012. 
53. Rockström, J.; Steffen, W.; Noone, K.; Persson, Å.; Chapin, F.S., III; Lambin, E.; Lenton, T.M.; Scheffer, M.; Folke, C.; Schellnhuber, H.J. Planetary Boundaries: Exploring the Safe Operating Space for Humanity. Ecol. Soc. 2009, 14. [CrossRef]

54. Najam, A. The Human Dimensions of Environmental Insecurity: Some Insights from South Asia. Environ. Chang. Secur. Proj. Rep. 2003, 9, 59-73.

55. Barnett, J.; Matthew, R.A.; O'Brien, K. Global environmental change and human security. In Globalization and Environmental Challenges; Springer: Berlin/Heidelberg, Germany, 2008; pp. 355-361.

56. Morrow, N.; Salvati, L.; Colantoni, A.; Mock, N. Rooting the Future; On-Farm Trees' Contribution to Household Energy Security and Asset Creation as a Resilient Development Pathway-Evidence from a 20-Year Panel in Rural Ethiopia. Sustainability 2018, 10, 4716. [CrossRef]

57. GEF. Global Environment Facility. Project Database. Internet. Washington, DC, USA, 2019. Available online: https://www.thegef. org/projects (accessed on 1 April 2018).

58. Hirschberg, J.; Manning, C.D. Advances in natural language processing. Science 2015, 349, 261-266. [CrossRef] [PubMed]

59. Goldberg, Y. A Primer on Neural Network Models for Natural Language Processing. J. Artif. Intell. Res. 2016, 57, 345-420. [CrossRef]

60. Salem, B. Application of GIS to biodiversity monitoring. J. Arid. Environ. 2003, 54, 91-114. [CrossRef]

61. AID DATA. 2017. Available online: https://www.aiddata.org/environment\#gef (accessed on 15 June 2017).

62. Raleigh, C.; Urdal, H. Climate change, environmental degradation and armed conflict. Politi. Geogr. 2007, 26, 674-694. [CrossRef]

63. ACLED. Armed Conflict Location \& Event Data Project. Africa 1997-2017 (Version 8). 2018. Available online: https://www. acleddata.com/data (accessed on 1 June 2017).

64. FAO. Food and Agricultural Organization of the United Nations GeoNetwork. Global Administrative Unit Layers (GAUL). Internet. Rome. 2018. Available online: https:/ /data.review.fao.org/map/catalog/srv/api/records/9c35ba10-5649-41c8-bdfceb78e9e65654 (accessed on 1 June 2017).

65. QGIS Software Version 3.0. Available online: https://www.qgis.org/en/site/ (accessed on 1 January 2017).

66. Pettersson, T.; Eck, K. Organized Violence, 1989-2017. J. Peace Res. 2018, 55, 535-547. [CrossRef]

67. Uppsala University. Uppsala Conflict Data Program. Uppsala, Sweden. 2018. Available online: http://ucdp.uu.se/\#/exploratory (accessed on 1 June 2017).

68. Strang, B.; van der Putten, P.; van Rijn, J.N.; Hutter, F. Don't Rule out Simple Models Prematurely: A Large Scale Benchmark Comparing Linear and Non-Linear Classifiers in OpenML. In International Symposium on Intelligent Data Analysis; Springer Nature: London, UK, 2018; pp. 303-315.

69. Zygomatic.nl. Wordcloud.Com. 2018. Available online: www.wordcloud.com (accessed on 15 April 2018).

70. Barrett, C.B. Food Aid Effectiveness: It's the Targeting, Stupid! Cornell University Applied Economics and Management Working Paper No. 2002-43; Cornell University Press: Cornell, NY, USA, 2002.

71. Dudley, J.; Ginsberg, J.; Plumptre, A.; Hart, J.; Campos, L. Effects of war and civil strife on wildlife and wildlife habitats. Conserv. Biol. 2002, 16, 319-329. [CrossRef]

72. Daskin, J.H.; Pringle, R.M. Warfare and wildlife declines in Africa's protected areas. Nature 2018, 553, 328-332. [CrossRef]

73. Hanson, T.; Brooks, T.M.; Da Fonseca, G.A.B.; Hoffmann, M.; Lamoreux, J.F.; Machlis, G.; Mittermeier, C.G.; Mittermeier, R.A.; Pilgrim, J.D. Warfare in Biodiversity Hotspots. Conserv. Biol. 2009, 23, 578-587. [CrossRef]

74. Braga-Pereira, F.; Peres, C.A.; Campos-Silva, J.V.; Santos, C.V.-D.; Alves, R.R.N. Warfare-induced mammal population declines in Southwestern Africa are mediated by species life history, habitat type and hunter preferences. Sci. Rep. 2020, 10, 15428. [CrossRef] [PubMed]

75. Clerici, N.; Armenteras, D.; Kareiva, P.; Botero, R.; Ramírez-Delgado, J.P.; Forero-Medina, G.; Ochoa, J.; Pedraza, C.; Schneider, L.; Lora, C.; et al. Deforestation in Colombian protected areas increased during post-conflict periods. Sci. Rep. 2020, $10,4971$. [CrossRef] [PubMed]

76. Singh, R.; Gan, M.; Barlow, C. What do rangers feel? Perceptions from Asia, Africa and Latin America. Parks 2020, 63-76. [CrossRef]

77. Homer-Dixon, T.F. Environment, Scarcity, and Violence; Princeton University Press: Princeton, NJ, USA, 2010.

78. Froese, R.; Schilling, J. The Nexus of Climate Change, Land Use, and Conflicts. Curr. Clim. Chang. Rep. 2019, 5, 24-35. [CrossRef]

79. Koubi, V. Climate Change and Conflict. Annu. Rev. Politi. Sci. 2019, 22, 343-360. [CrossRef]

80. Brzoska, M. Weather Extremes, Disasters, and Collective Violence: Conditions, Mechanisms, and Disaster-Related Policies in Recent Research. Curr. Clim. Chang. Rep. 2018, 4, 320-329. [CrossRef]

81. Tollefsen, A.F. Experienced poverty and local conflict violence. Confl. Manag. Peace Sci. 2017, 37, 323-349. [CrossRef]

82. Gaynor, K.M.; Fiorella, K.J.; Gregory, G.H.; Kurz, D.J.; Seto, K.L.; Withey, L.S.; Brashares, J.S. War and Wildlife: Linking Armed Conflict to Conservation. Front. Ecol. Environ. 2016, 14, 533-542. [CrossRef]

83. Douglas, L.R.; Alie, K. High-value natural resources: Linking wildlife conservation to international conflict, insecurity, and development concerns. Biol. Conserv. 2014, 171, 270-277. [CrossRef]

84. Buhaug, H.; von Uexkull, N. Vicious Circles: Violence, Vulnerability, and Climate Change. Annu. Rev. Environ. Resour. 2021, 46, 545-568. [CrossRef] 
85. Tseng, T.-W.J.; Robinson, B.E.; Bellemare, M.F.; BenYishay, A.; Blackman, A.; Boucher, T.; Childress, M.; Holland, M.B.; Kroeger, T.; Linkow, B.; et al. Influence of land tenure interventions on human well-being and environmental outcomes. Nat. Sustain. 2020, 4, 242-251. [CrossRef]

86. Heger, M.; Zens, G.; Bangalor, M. Does the Environment Matter for Poverty Reduction? The Role of Soil Fertility and Vegeta-tion Vigor in Poverty Reduction; The World Bank: Washington, DC, USA, 2018.

87. Castro-Nunez, A. Responding to Climate Change in Tropical Countries Emerging from Armed Conflicts: Harnessing Climate Finance, Peacebuilding, and Sustainable Food. Forests 2018, 9, 621. [CrossRef]

88. Läderach, P.; Ramirez-Villegas, J.; Caroli, G.; Sadoff, C.; Pacillo, G. Climate finance and peace-tackling the climate and humanitarian crisis. Lancet Planet. Health 2021, 5, e856. [CrossRef]

89. Busby, J.W. Beyond internal conflict: The emergent practice of climate security. J. Peace Res. 2020, 58, 186-194. [CrossRef] 